\title{
Articulating intermodal chains through short-sea shipping: a method for assessing the performance of East African ports
}

\author{
Alba Martínez-López (D) and Manuel Chica González (D) \\ Naval Architecture Unit, Department of Mechanical Engineering, University of Las Palmas de Gran Canaria, Escuela \\ de Ingenierias Industriales Y Civiles (Campus de Tafira), Las, Canary Islands, 35017, Spain
}

\begin{abstract}
The location of East African ports, along with difficulties in building and maintaining effective road corridors, has led to the consideration of intermodal transport through Short Sea Shipping (SSS) as an alternative for load transport. However, this potential solution is dependent on the ports as consolidation load centres and on the configuration of transport networks. This paper provides a method to evaluate the performance of East African ports in their role as a hub for the intermodal chain. Specifically, through an assessment of port indicators ad hoc, the method jointly evaluates the performance of the hinterland's capillary haul and port operations. The proposed indicators aggregately consider attributes of time and cost and compare competitiveness for ports' current status with standard parameters. The application of the method to East African ports reveals that their tariff structure should be adapted to the operative reality of SSS. In addition, the loading time has not proven to be as determinant as the pre-berthing waiting time in the effectiveness of the intermodal chains.
\end{abstract}

\section{KEYWORDS}

Short sea shipping; port performance method; intermodal chains; East African ports

\section{Introduction}

The relevant literature has frequently demonstrated that Short Sea Shipping (SSS) is a convenient trunk haul for intermodal transport (Trujillo and Martínez-López 2021). When this is feasible, SSS is the leading option for two main reasons: because it requires low infrastructure investment and because it can take advantage of economies of scale by using vessels. Both reasons are very convenient regardless of the localization of the transport service; however, they are especially significant in regions where load transport by land is difficult. This is the case of various Eastern Africa countries, where maintenance costs for the land corridors are elevated in relation to the size of the economies, and road connections are often incomplete.

Taking into account the main container routes in East Africa (Far East-Europe in the North and Far East-South Africa in the South) and the location of the continent's ports, it is likely that Aden, Djibouti and Berbera in the North, and Durban in the South, will continue to feed the other East African ports (Haralambides et al. 2011) in the foreseeable future. This means that the majority of East Africa ports will become regional hubs (Haralambides et al. 2011), where their utility will largely be contingent on their effectiveness as load distribution centres.

CONTACT Alba Martínez-López alba.martinez@ulpgc.es Department of Mechanical Engineering (Naval Architecture Unit), University School of Civil and Industrial Engineering (Campus of Tafira), Las Palmas De Gran Canaria, CP:35017, Spain This article is a revised and expanded version of a paper entitled: Assessment of the feasibility of the Eastern African ports to articulate intermodal chains through Short Sea Shipping presented at The Annual Conference of the International Association of MaritimeEconomists (IAME), Athens University of Economics and Business, Athens, Greece, June 2019. The conference organisers have given copyright permission to publish the revised articles in MPM. 
The high costs of crossing borders by road together with the great distance that separates most East African ports from the arterial container routes suggest that intermodality through SSS might be indeed the most effective transport mode between landlocked countries and those affected by port hinterlands. However, the feasibility of this option lies in the effectiveness of the role played by the ports as load consolidation centres. Despite its relevance, very few publications have sought to assess this port attribute from a methodological standpoint (Ha, Yang, and Seo 2021). The port performance indicators (PPIs) have been largely attended by previous researchers, with a particular emphasis on port sustainability indicators in recent years; nevertheless, the evaluation of the ports as hubs in intermodal chains has been predominantly constrained to 'classical operational port indicators', without establishing interdependencies among them (fragmented approaches, Ha, Yang, and Seo 2021). This paper contributes to fill this knowledge lack by providing an aggregated method that enables, through a single indicator, a port to be assessed as a load consolidation centre in an intermodal chain articulated through SSS. Additionally, the method overcomes the limitations of previous approaches to SSS in port by integrating not only the port effectiveness in terms of time and costs in a single indicator but also considering the kinds of vessels that are able to operate under SSS conditions and the performance of the capillary hauls' interfaces for the assessment.

Given the aforementioned potential of SSS for load transport in East Africa, the introduced method adapts to the features of Eastern African ports in order to identify their weak points as load consolidation centres and their utility within the intermodal chain. This [method offers a relative evaluation to a standard, this allows to maximize the method's utility as a decision tool for a number of stakeholders (deviation analysis) and for port benchmarking. The application case to the Eastern African ports has assumed as standard values those obtained from a medium-size European port that operates as a hub in intermodal chains. In this way, the findings of this paper will be useful not only for Port Authorities that play a key role in the region's port government but also for policymakers that seek global transport solutions.

This paper is organized as follows: section 2 presents a brief literature review on port performance measures, focusing on intermodality competitiveness. Section 3 provides details about the assessment methodology of the ports as load consolidation centres (Port Indicators). The section also introduces calculation models for the competitiveness parameters of intermodal transport through SSS. Section 4 summarizes the simulations carried out for several East African ports and specifies the methodology introduced above. Finally, section 5 details the main insights drawn from the application case and suggests how to increase the possibilities of success of the intermodal option in East Africa.

\section{A brief literature review}

A number of authors have analyzed the effectiveness of ports on the feasibility of intermodality through SSS, especially in terms of time. Johnson and Styhre (2015) identified that SSS vessels in the North and Baltic seas may spend up to $40 \%$ of their time in ports, and that half of this time was unproductive. The authors recommended increasing energy efficiency for the SSS fleet by reducing port waiting times. Also, from the Baltic region, $\mathrm{Ng}$ (2009) concluded that the feasibility of intermodal chains in the European Union (E.U.) was necessarily subject to an improvement in port efficiency. This finding was supported by Suárez-Alemán, Trujillo, and Culliane $(2014,2015)$, who also concluded that the competitiveness of the whole intermodal chain (mainly determined by the attributes of time and cost -Martínez-López, Alonso, and Munín 2015b) articulated through SSS is actually [subject to the port performance as a consolidation centre of the load and modal shift centre and therefore, the port should be assumed to be an extension of the road (Trujillo and Martínez-López 2021). This last port dimension for SSS activity was also highlighted by Sambracos and Maniati (2012), who emphasized that the road network performance of port hinterlands is a key 
attribute for intramodality in Greek ports. Likewise, Vermeiren and Macharis (2016) confirmed that cost is the dominant attribute in intermodal choice, as shippers' preferred port is the one that articulates the lowest cost chain.

Despite the unquestionable relation between port performance and the competitiveness of the intermodal chain, Port Performance Indicators (PPIs) seldom involve specific indicators for multicriteria approaches to SSS activity. In this regard, Ha, Yang, and Seo (2021) noted the lack of systematic methods in the literature to evaluate port performance jointly from multi-criteria perspectives. This has led to fragmented approaches to ports' complex-reality through the analysis of independent PPIs in several areas (Ha et al. 2017; Ha, Yang, and Seo 2021). So, while lead-time indicators have gained prominence in recent years (the speed at which activities are performed: vessel turnaround, truck turnaround, container dwell time) to evaluate the intermodal role of the ports, some authors have also proposed complementary indicators. De Langen and Sharypova (2013), for example, proposed intermodal connectivity indicators (relative indicators), while Shiau and Chuang (2015) and Di Vaio, Varriale, and Alvinoa (2018) published port and key sustainability indicators, respectively. Recent research has focused on advancing understanding of the relationships among PPIs (Ha and Yang 2017), and their interdependency, to improve decision-making methods in port. This research line suggests modelling these interdependencies by considering a number of stakeholders' perspectives (Ha et al. 2017), in order to provide global assessments in port. Despite this trend, there is still no port performance method in the literature that focuses on SSS operations from the standpoint of overall-chain competitiveness.

Based on the above, this work contributes to filling this research gap through the definition of a method that can provide an aggregated PPI that focuses on SSS activity as a part of the intermodal chain. The proposed evaluation method provides an assessment in relative terms regarding standard values (previously determined by the stakeholders) to maximize its utility as a decisionmaking tool. Due to the interest in SSS as a suitable solution for freight transport in the East African region, the method presented in the following sections is adapted to the East African port reality.

\section{Assessment methodology}

Although the competitiveness of transport modes can be evaluated through numerous attributes, two stand out: 'total cost' and 'final time invested in the transport service'. In fact, both parameters are often considered in the assessment of the competitiveness of intermodality versus road transport (Martínez-López, Alonso, and Munín 2015b). These studies usually analyze the performance of 'door to door' transport through different modes by assuming a determined transport network. However, this approach is not applicable to East Africa due to the lack of unimodal alternatives (lack of road continuity in countries). On the other hand, an evaluation of a ports' performance without considering the transport network might lead to erroneous conclusions about the feasibility of intermodal chains, since ports must be considered as an extension of the road in the chains (Sambracos and Maniati 2012; Trujillo and Martínez-López 2021).

In light of the above, the assessment method that is introduced in this work analyzes the competitiveness of the intermodal chain through the ports' performance as load consolidation centres from/towards the final nodes. Specifically, the evaluation is jointly undertaken for the land haulage in the capillary hauls and cargo operation in the consolidation centres (ports). Thus, Port Indicators $\left(P I_{m} ; \forall m \in \mathrm{M}\right.$, see Glossary) assess ports $(\forall m \in \mathrm{M})$ in accordance with their real capacity to integrate specific intermodal chains. Consequently, the calculation of this indicator requires specific information about land stretches to be considered (location of the end points of the chainnodes in relation to the ports and the tier of the corridors) along with the performance of the port services involved in SSS traffic (facilities, effectiveness of the cargo handling systems, cargo dwell time, ship turnaround time and port duties (for the SSS vessels). 
Port Indicators $\left(\mathrm{PI}_{\mathrm{m}} ; \forall m \in \mathrm{M}\right.$, see equation 1$)$ integrates the assessment of the competitiveness of intermodality in terms of time $\left(\mathrm{PI}^{\mathrm{T}}{ }_{\mathrm{m}} ; \forall m \in \mathrm{M}\right)$ and cost $\left(\mathrm{PI}^{\mathrm{C}}{ }_{\mathrm{m}} ; \forall m \in \mathrm{M}\right)$ under the conditions previously mentioned. As can be seen in equation 1 the same weighting factor will be assumed for both attributes. These Indicators of attributes $\left(\mathrm{PI}^{\mathrm{T}}{ }_{\mathrm{m}}\right.$ and $\left.\mathrm{PI}^{\mathrm{C}}{ }_{\mathrm{m}} ; \forall m \in \mathrm{M}\right)$ integrate port performance for all possible vessels that are able to operate in SSS $(\forall q \in \mathrm{Q}$, see equations 2,3 and the Glossary).

$$
\begin{gathered}
\mathrm{PIm}=\frac{1}{2} *(\mathrm{PITm}+\mathrm{PIcm}) \cdot \in M \\
\mathrm{PITm}=1 / 3 * \sum_{q=1}^{3} \text { PITmq } \cdot \forall \mathrm{m} \in \mathrm{M} \cdot \forall q \in Q \\
\mathrm{PICm}=1 / 3 * \sum_{q=1}^{3} \text { PICmq } \cdot \forall \mathrm{m} \in \mathrm{M} \cdot \forall q \in Q
\end{gathered}
$$

For the calculation of the Port Indicators, the values calculated for every port $(\forall m \in \mathrm{M}$, see equation 1), with information about the port and its hinterland, are compared with the values obtained for these ports and their hinterlands, but using standard values that involve a reference line for all ports, which allows benchmarking to be undertaken. For the application case in East African ports, the standard values were obtained from a medium-size European port with SSS activity. This assumption was made for two reasons: to establish a comparison with accurate and well-known data, and to enlarge its utility for stakeholders by providing information about deviations and their possible reasons.

equations 4 and 5 show, through Port Indicators in terms of time and cost $\left(\mathrm{PI}^{\mathrm{T}}{ }_{\mathrm{mq}}\right.$ and $\mathrm{PI}^{\mathrm{C}}{ }_{\mathrm{mq}}$, see equations 2 and 3), the relationships between the current values for time $\left(\mathrm{TMT}_{\mathrm{mq}}\right)$ and cost $\left(\mathrm{CMU}_{\mathrm{mq}}\right)$ of the chain, and those standard values $\left(\mathrm{TMT}_{\mathrm{q}}^{\mathrm{S}}\right.$ and $\left.\mathrm{CMU}_{\mathrm{q}}^{\mathrm{S}}\right)$ :

$$
\begin{gathered}
\text { PITmq }=1-\frac{\text { TMTmq }}{\text { TMTmq }+ \text { TMTSq }} \cdot \forall \mathrm{m} \in \mathrm{M} \cdot \forall q \in Q \\
\text { PICmq }=1-\frac{C M U \mathrm{mq}}{\text { CMUmq }+ \text { CMUSq }} \cdot \forall \mathrm{m} \in \mathrm{M} \cdot \forall q \in Q
\end{gathered}
$$

Therefore, port indicators $\left(P I_{m} ; \forall m \in M\right.$, see equation 1) offer useful information about the performance of the ports in relation to a standard. This allows us to handle unitary values for the indicators and to know the possible deviations from a common reference line. Thus, the closer the Port Indicator is to one, the greater the competitiveness of the port to articulate intermodal chains. Despite the fact that not all the necessary variables for calculating the times and costs of the chain $\left(\mathrm{TMT}_{\mathrm{mq}}\right.$ and $\mathrm{CMU}_{\mathrm{mq}}$ ) are dependent on the ports (for example, a unitary cost of the road, the normative of transport about load transport, the geographical location of the ports and end pointnodes of the capillary hauls), most are defined by them or can even be modified by their activity.

\subsection{Calculation of the competitiveness of the intermodal chains through SSS}

The calculation of Port Indicators requires intermodality competitiveness in terms of time (TMT) and cost (CMU) to be defined for every evaluated port $(\forall m \in M)$ by considering both their current performance and their standard performance. The following sections show the adaptation to the Eastern Africa context of the mathematical models published by Martínez-López, Kronbak, and Jiang (2015a) about time and cost for SSS. 


\subsubsection{Transport networks}

Based on the previous definition of transport networks (Road/SSS/Road-Road/SSS/Long Sea Shipping) (Paixao Casaca 2008; Martínez-López, Alonso, and Munín 2015b) it is necessary to calculate the attributes of intermodality. This chain will be defined in accordance with the transport models suggested by Daganzo (2005): 'many to one'. That is, many possible origins/destinations of the load (nodes) on land for only one consolidation centre (hub) (see Figure 1). This transport model is a simplification of the classical models for intermodal chains through SSS: 'many to many' transport networks (see Figure 1 and the Glossary): several capillary hauls on both coasts, and one trunk haul.

The 'many to many' model is appropriate to analyze the whole-chain performance ('door to door' transport). In order to meet this aim, the seaborne stretch should be previously known and should respond to SSS traffic. Although most East-African ports can act as SSS ports, no consolidated routes currently exist for this purpose. Additionally, some of the most

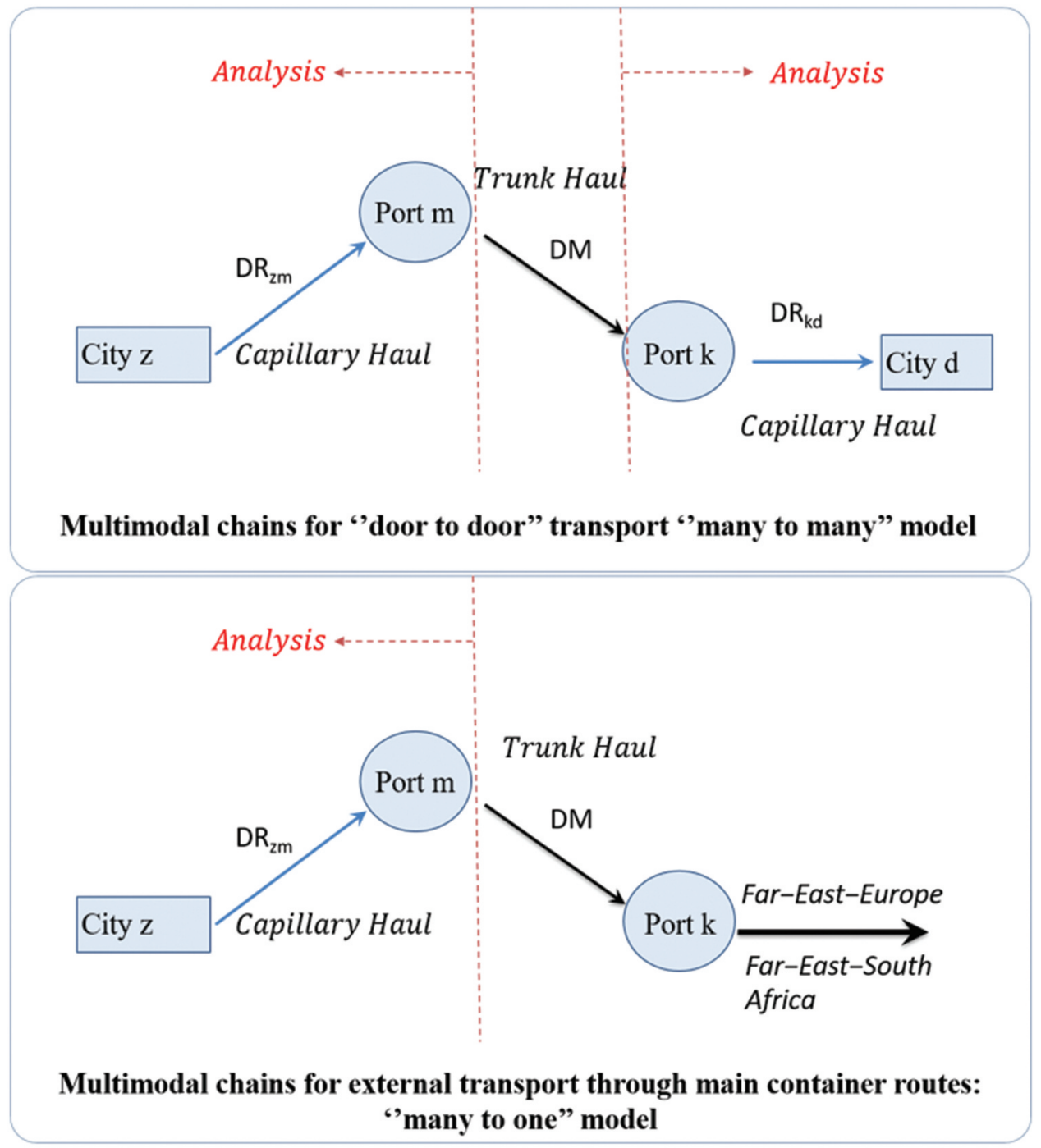

Figure 1. Analyzed chain in the transport models. 
representative East Africa ports; Djibouti in the North (233 nautical miles away from the Far East-Europe route) and Durban in the South (103 nautical miles away from the Far East-South Africa route) play the role of hub ports by feeding Eastern Africa through a hub and spoke traffic system.

Consequently, the transport model used will be a 'many to one' model that will not consider the trunk hauls. Therefore, the chain assessment will focus on the stretches from the extreme points, (the network nodes - rectangles in Figure 1-) to the ports (consolidation terminals circles in Figure 1, see Glossary). To simplify the study, the number of nodes considered was limited to three extreme points for each port, and the relative probability of delivering or receiving a cargo unit $\left(X_{z}, \forall \mathrm{z} \in \mathrm{Z}\right.$ and $X_{d} ; \forall \mathrm{d} \in \mathrm{D}$, see Glossary) responds to population criteria ( $\mathrm{Ng}$ 2009). Thus, it is assumed that the highly populated centres are also the main goodsgenerating centres.

The hubs' networks: The following ports are assumed to be hubs of the transport networks (consolidation centres): Djibouti (Djibouti), Berbera (Somalia), Lamu (Kenya), Mombasa (Kenya), Dar es Salaam (Tanzania), Nacala (Mozambique), Beira (Mozambique), Maputo (Mozambique), Durban (South Africa), East London (South Africa), Toamasina (Madagascar) and Port Louis (Mauritius). Despite the prime locations of the latter two ports (on the Singapore-Durban route), these ports have been ruled out due to the fact that their activity is mainly focused on the transshipment market.

The networks' nodes: the hinterlands of the East African ports reach landlocked countries and therefore, their 'influence areas' are especially wide. In fact, whereas the coastal countries almost exclusively use their own ports to transport their products, the landlocked countries use several ports; a point that favours competitiveness (Haralambides et al. 2011), and therefore their hinterlands are overlapping in the landlocked countries (Haralambides et al. 2011).

The following criteria have been employed to select the hinterlands' nodes: Population, Main generating centres for container goods, ${ }^{1}$ Average distance to the port, Existence of land infrastructures to achieve the ports, and availability of ports' transit data flows.

Finally, the selected nodes belong to the following countries:

- Coastal countries: Djibouti, Somalia, Kenya, Tanzania, Mozambique, South Africa, Mauritius, and Madagascar

- Landlocked countries: Ethiopia, South Sudan, Uganda, Zambia, D.R. Congo, Malawi, Zimbabwe, Swaziland and Botswana

Table 1 shows the nodes $(z)$ that can be reached by ports $(m)$ and the land distances for the capillary hauls of the transport networks $\left(D R_{z m} ; \forall \mathrm{z} \in \mathrm{Z} \wedge \forall \mathrm{m} \in \mathrm{M}\right.$, see Figure 1 and the Glossary). Taking into account the criteria previously detailed, three nodes were selected per hub (port). In this selection domestic cargo was also considered and the chosen nodes are highlighted in bold font in Table 1 . This Table also shows values marked with asterisks. The numbers with one asterisk $\left.{ }^{*}\right)$ indicate the minimum distance by land from the node to the port, when that node can be served by different ports. In turn, two asterisks $\left(^{* *}\right)$ determine the main origins and destinations for the ports from the landlocked countries according to the flow data (Haralambides et al. 2011). Among the landlocked countries, the prime location of Mombasa and Beira is noteworthy. Mombasa offers the best option in terms of distance for South Sudan and Uganda, whereas Beira represents the most effective option for the copper belt of Zambia, Malawi and Zimbabwe.

Taking into account the high influence of vessel loading strategies on the competitiveness of intermodal transport (Morales-Fusco, Sauri, and Lago 2012), the models consider all kinds of suitable vessels for SSS $(\forall \mathrm{q} \in \mathrm{Q}$, see Glossary): feeder container vessels, Ro-Ro vessels and Ro-Pax vessels along with their respective cargo units, TEU and 5-axle trucks with an average cargo capacity of 12.5 and 24 tonnes, respectively $\left(P_{p} ; \forall p \in P P\right.$, see Glossary). Likewise, for all cases of Ro-Ro traffic, the models will assume accompanied cargoes for trucks but without drivers (Paixao and 
Marlow 2002; Marlow and Paixao Casaca 2004) and the most unfavourable situation-first in, last out-. Finally, the models will assume that the loading operation is carried out by their own drivers for Ro-Pax vessels (no port drivers).

For the calculations, the models have assumed the technical features of the vessels (see Table 2), which are operating under SSS conditions in the European Union (Unifeeder shipping company, Britany Ferries and Suardiaz Shipping Company). These fleets can be assumed since their operation on SSS routes is consolidated.

\subsubsection{The time model}

In order to calculate Port Indexes in terms of time $\left(\mathrm{PI}^{\mathrm{T}}{ }_{\mathrm{mq}} ; \forall \mathrm{m} \in \mathrm{M}^{\wedge} \forall \mathrm{q} \in \mathrm{Q}\right.$ see equation 4), intermodal time (TMT) must be calculated through a time model.

$$
T M T=T+T M=T+T P+T S 2+T S 3
$$

The time model put forward by Martínez-López, Kronbak, and Jiang (2015a) will be adapted to the Eastern African context. In this model, the times are measured in all cases in hours per cargo unit and trip. The intermodal time (TMT, see equation 6) integrates the time invested in maritime transport (TM) and the time of the land legs (T) of the transport network (see Figure 1 and 2).

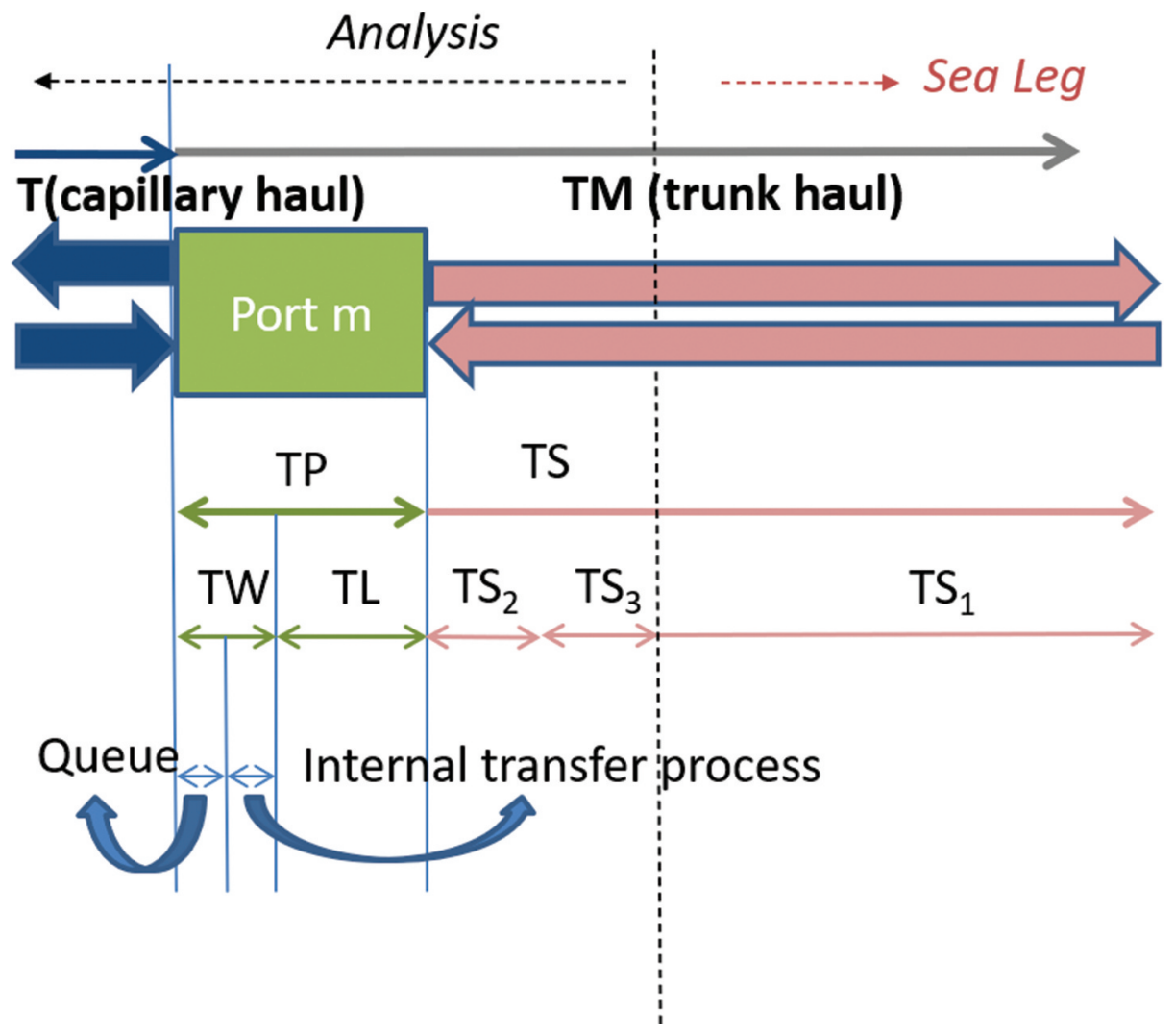

Figure 2. Time structures for the trunk haul of the intermodal transport network. 


\subsubsection{Time invested in capillary hauls $(T)$}

Equation 7, a step function (Sandberg-Hanssen, Mathisen, and Jorgensen 2012), shows the adaption of the initial equation to the East Africa framework. The initial model for the calculation of the times consumption on capillary hauls-(T), considered the national normative on speeding (VT), maximum daily driving times for the load (Max) and minimum driving rest times (Rest). However, the adaption of this model to the East Africa reality forces us to also consider the waiting times for administrative procedures at borders (sometimes over a day, for example, to cross the border from Kenya to Uganda; Teravaninthorn and Raballand 2009) and the 'good and fair' conditions of the roads.

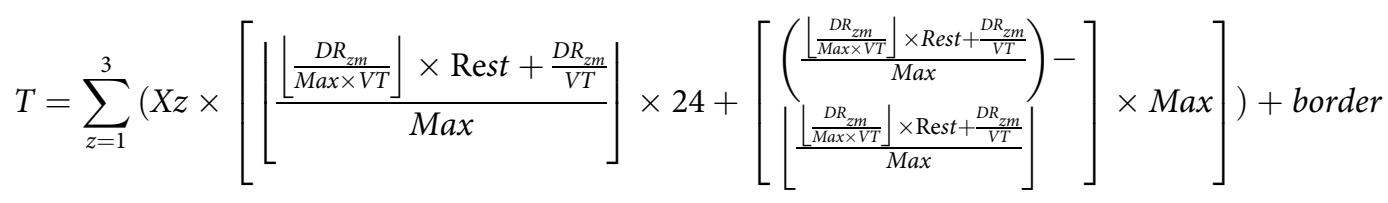

Thus, the variables Max and Rest will be calculated from real values of total times invested in the transport of the different corridors, in the case of this study: East Africa and Southern Africa, taking into account, besides this, an additional time (border crossing time of $24 \mathrm{~h}$ ) for crossing the border when that occurs. The information about these corridors published by Teravaninthorn and Raballand (2009) along with those offered by Monthly Port Community Charter Report (May 2018 ${ }^{2}$ ) (The Northern Corridor Transit and Transport Coordination AuthorityNCTTCA-) have led us to define the values shown in Table 3.

This table also collects the corresponding values for the European standard when the port is evaluated under standard conditions. The values in this case are obtained from the European regulation regarding maximum driving time per day, the minimum rest times during driving (Regulation CE 561/2006) and the maximum road speed for load (92/24/CE and 92/6/CE). Likewise, $50 \mathrm{kM} / \mathrm{h}$ will be taken as the value for $(V T)$ when a corridor in Africa has good conditions in all seasons (Teravaninthorn and Raballand 2009)

\subsubsection{Time invested in the trunk haul (TM)}

Figure 2 shows all the times collected in the trunk haul of the intermodal chain (TM) that will be considered in the analysis. The port time $(T P)$ includes the waiting time in port $(T W)$ and the loading time invested $(T L)$.

The following were taken into account for the calculations:

(1) Loading time (TL) can be assumed to be identical in both directions (loading and unloading).

(2) Waiting time (TW) includes the internal transfer process for the cargo units. The waiting time (TW) also involves the queue time for boarding the trailers and trucks in the Ro-Ro traffic, whereas for Lo-Lo traffic, waiting time is related to a semi-direct route for the containers (Taleb-Ibrahimi, 1989) with three trans-shipments (from truck to operation zone, the transfer from operation zone to the dock and the time invested for loading from the dock to the vessel) and the time invested for the reception process of the containers. The waiting time is different in both directions (TW); the entry waiting time (from the vessel) is equivalent to the cargo container dwell time. Whereas the approach to the exit waiting time (from the land) is estimated through the following port indicators: One Stop Centre Clearance Time, Delay after Customs Release and the Time Taken at the Document Processing Centre. In the analysis, in order to simplify the calculations, a symmetric time operation in both directions will be considered; therefore, the average between entry and exit waiting time will be taken. 
(3) Only the components of the shipping time (TS) related to port operations: the pilot service $\left(\mathrm{TS}_{2}\right)$ and the towing service $\left(\mathrm{TS}_{3}\right)$ will be considered (the sailing time - $\mathrm{TS}_{1^{-}}$, will not be considered-see equation 6). Strictly, both times $\left(\mathrm{TS}_{2}\right.$ and $\left.\mathrm{TS}_{3}\right)$ can be assumed to take equal values in both directions. However, again the real time invested in the entry of a vessel is different from that of the exit time. This is mainly due to the Actual Ship Waiting Time (the waiting time for the ship from its arrival at the fairway buoy to 'pilot onboard'). As this point is a relevant port performance indicator, again both times (entry and exit) will be considered in a symmetric way for the simulation. In such a way, the total time spent on the port by the ship (turn-around ship time) will be integrated by two identical times: entry and exit times.

\subsubsection{The costs model}

The calculation of the costs of the intermodal chains (CMU) is necessary to determine the Port Indicators in terms of cost $\left(\mathrm{PI}_{\mathrm{mq}}^{\mathrm{C}} ; \forall \mathrm{m} \in \mathrm{M} \wedge \forall \mathrm{q} \in \mathrm{Q}\right.$ see equation 5).

Figure 3 shows the total cost of the intermodal chain (CMU), which collects all costs of the capillary hauls $\left(\mathrm{CMU}_{1}\right)$ and trunk hauls $\left(\mathrm{CMU}_{2}\right)$ (Martínez-López, Kronbak, and Jiang 2015a). However, for this study CMU involves, aside from the costs of the land stretches $\left(\mathrm{CMU}_{1}\right)$, only some of those of the trunk haul $\left(\mathrm{CMU}_{2}\right.$ see Figure 3$)$ for analysis.

The development of the costs model for trunk haul ( $C M U_{2}$ trunk haul) in intermodal transport was carried out by calculating the break point (accounting criterion) for an SSS service that integrates all the possible variables (see figure 4). The model, which was developed by MartínezLópez, Kronbak, and Jiang (2015a) to calculate trunk haul $\left(C M U_{2}\right)$, follows the same structure for all kinds of vessels $\left(\forall \mathrm{q} \in \mathrm{Q}\right.$ ) by integrating the following items: (amortization costs $C T_{1}$, financing costs $C T_{2}$, insurance $C T_{3}$, maintenance $C T_{4}$ and crew costs $C T_{5}$ and fuel costs $C T_{6}$ ), only the operational port costs will be considered in this analysis because they are dependent on the port and stowage companies (ship duties $C T_{7}$, load duties $C T_{8}$, pilot duties $C T_{9}$, towing duties $C T_{10}$, mooring

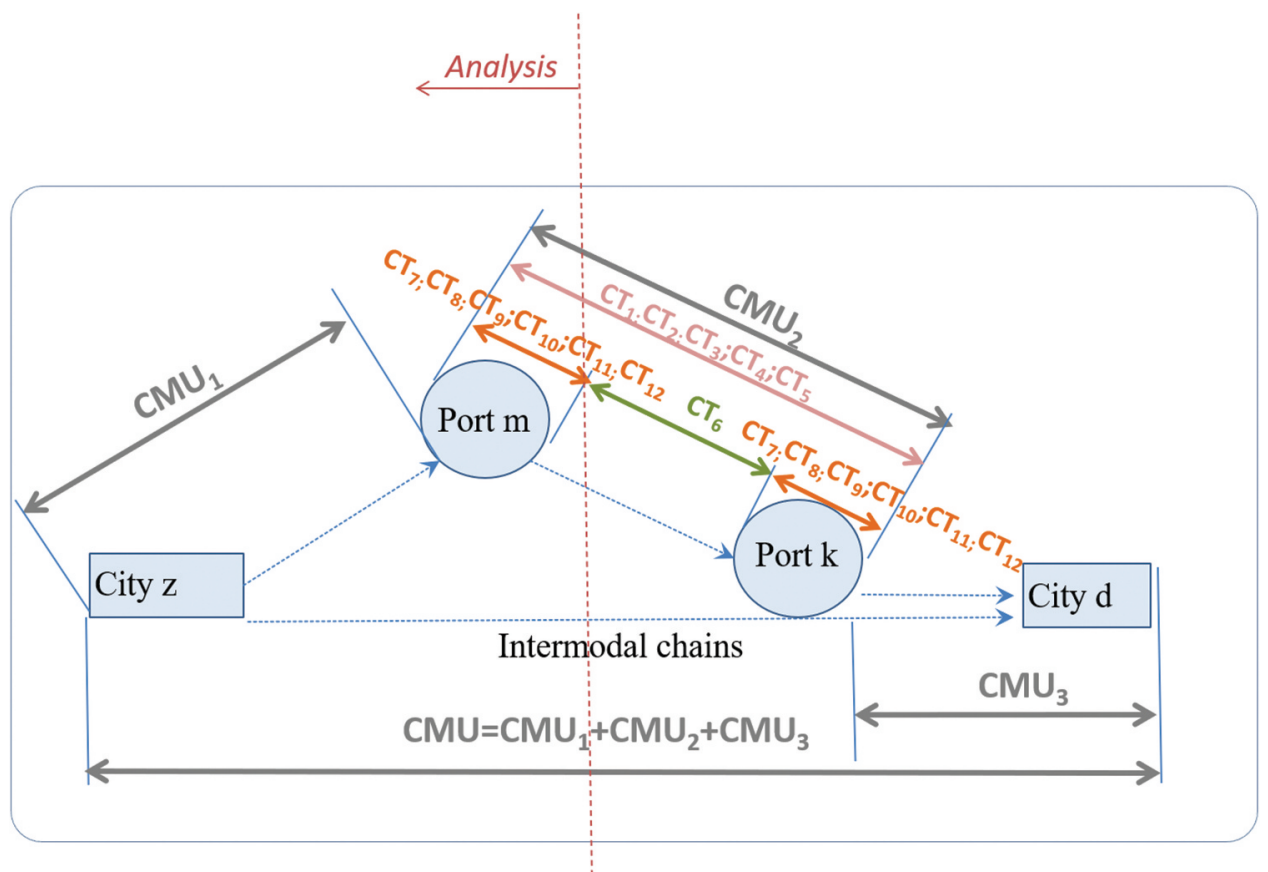

Figure 3. Cost structure for the intermodal transport network. 
duties $C T_{11}$ and loading costs $\left.C T_{12}\right)$. However, due to the nature of this study only the costs of the land stretches $\left(C M U_{1}\right)$ and those of the trunk haul related with the port services are taken into account $\left(C T_{7}-C T_{12}\right)$.

Equation 8 shows the costs for land stretches $\left(\mathrm{CMU}_{1}\right)$ aside from the distances between nodes and hubs ( $\mathrm{DR}_{\mathrm{zm}}, \forall m \in \mathrm{M} \wedge \forall q \in \mathrm{Q}$ see Figure 1 and the Glossary), consider unitary costs per kilometer $(C K)$ and the weight of the cargo units $\left(P_{p} ; \forall p \in P P\right)$ for all possibilities (TEUs and trucks) as the results are given in dollars per ton.

$$
C M U 1=\left(\frac{C K}{P p}\right) \times\left(\sum_{z=1}^{3}\left(X z \times D R_{z m}\right) \forall p \in P P\right.
$$

This analysis has considered the unitary costs of five-axle heavy-duty vehicles (HDV) able to transport refrigerated cargo (maximum net cargo, $24 \mathrm{t}$ ). The comparison published by Teravaninthorn and Raballand (2009) for the unitary costs of freight transport by road (CK) for different African corridors in relation to the unitary costs of European countries is used to determine the unitary costs for the Southern and Eastern corridors in Africa for $2017(1.206 \$ / \mathrm{kM}$ for the Eastern African corridor, $1.629 \$ / \mathrm{kM}$ for the Southern corridor and $1.441 \$ / \mathrm{kM}$ for the European standard).

\section{Performance of the Eastern African ports as consolidation centres of the load for intermodal chains}

This section includes a performance analysis of the intermodal chains articulated through East African ports (see section 3.1.1) under the conditions specified above. As an example of the application of this methodology, the simulations of three ports will be shown: Djibouti in the North, Mombasa in the central region and Durban in the South. Despite the fact that the seaborne stretch will not be analyzed in these simulations (see section 3.1.1), it is interesting to bear in mind that, for all East African ports identified in section 3.1.1 there are feasible maritime routes to operate under SSS conditions (from 300 to $600 \mathrm{~nm}$., see Table 2). Namely, all identified ports have possible trunk hauls for their intermodal chains, and therefore there is interest in analyzing their feasibility.

This analysis is carried out through the calculation of the Port Indicators; thus,: the closer the indicator value is to one, the greater is the competitiveness of the port to articulate intermodal chains (see equations 1 to 5 ). In turn, when the indicator value is more than 0.5 , the advantage will be favourable to the evaluated port $(\mathrm{m})$ in relation to the European standard port. Moreover, in order to provide further information about port performance, the expressions 4 and 5 that are relative to the kind of vessel, will be also applied to the main items that integrate the attributes of time and cost in the intermodality (see sections 3.1.2 and 3.1.3).

\subsection{Simulations}

Vigo port (in the North-West of Spain) has been selected as a European standard port due to its medium size, its long period of SSS activity (since the 1950s), and the accuracy of available operational information. Additionally, since 2015, Vigo has been part of a recognized Motorway of the Sea between Spain and France (Vigo-St.Nazaire, ${ }^{3}$ with 494 nautical miles). Thus, its performance has been considered in all simulations to calculate standard values of competitiveness $\left(\mathrm{TMT}_{\mathrm{q}}^{\mathrm{S}}\right.$ and $\left.\mathrm{CMU}_{\mathrm{q}}^{\mathrm{S}} ; \forall \mathrm{q} \in \mathrm{Q}\right)$ for the intermodal chains. The data used for the simulations of the ports are related to 2017 values (see Appendix I-IV). However, when performance data were not found for the African ports, these were taken from the standard values (note that the loading/ unloading rate for Ro-Ro cargo-berth productivity for rolled cargo-was not found for Djibouti and Mombasa, so the European standard values were assumed for these ports). 
Table 4 shows the final Port Indicators ( $\mathrm{PI}_{\mathrm{m}} ; \forall m \in \mathrm{M} \wedge \forall q \in \mathrm{Q}$ see equation 1 ) for the evaluated Eastern African ports. The table indicates the ports' position according to their performance as a consolidation centre for intermodal chains through SSS. According to the results obtained, Mombasa reaches the highest value and therefore its performance is closest to the European standard, followed by Durban and Djibouti. In order to obtain further information about these values, Tables 5 and 6 collect information about the Port Indicators in terms of time $\left(\mathrm{PI}^{\mathrm{T}}{ }_{\mathrm{m}}\right.$ and $\mathrm{PI}^{\mathrm{T}}{ }_{\mathrm{mq}}, \forall m \in \mathrm{M} \wedge \forall q \in \mathrm{Q}$ see equations 2 and 4$)$ and cost $\left(\mathrm{PI}^{\mathrm{C}}{ }_{\mathrm{m}}\right.$ and $\mathrm{PI}^{\mathrm{C}}{ }_{\mathrm{mq}}, \forall m \in \mathrm{M} \wedge \forall q \in \mathrm{Q}$ see equations 3 and 5). Table 5 shows that no Port Indicator achieves 0.5 and therefore, no port of those analyzed reaches European standards in terms of time.

Among the Eastern African ports, Durban $\left(\mathbf{P I}^{\mathbf{T}}{ }_{\mathbf{3}}=\mathbf{0 . 3 1}\right)$ and Mombasa $\left(\mathrm{PI}^{\mathrm{T}}{ }_{\mathbf{2}}=\mathbf{0 . 3 0}\right)$ offer better performance than Djibouti $\left(\mathbf{P I}^{\mathbf{T}}{ }_{\mathbf{1}}=\mathbf{0 . 2 1}\right)$. This is so, mainly due to the time invested in the land stretch $\left(P I^{T}{ }_{1}=0.06\right.$ for Djibouti against $P I^{T}{ }_{2}=0.13$ for Mombasa and $P^{T}{ }_{3}=0.16$ for Durban respectively, see Table 5) that follows a steps trend according to the transport network defined by the distances between the extreme nodes (see Table 1) of the hinterlands to the ports (Average distance for Djibouti: $656 \mathrm{~km}$, Mombasa: $781 \mathrm{~km}$ and Durban: $869 \mathrm{~km}$ ).

However, aside from the land stretch, Djibouti also shows the highest deviation regarding the European standard port in the maritime stretch (item 1.2 of the Table $5, P I^{T}{ }_{1}=0.27$ against $P I^{T}{ }_{2}=0.41$ and $P I^{T}{ }_{3}=0.39$ ). The excessive port times for the cargo (see section 1.2.1 in Table $5-P I^{T}{ }_{1}=0.28$-) with 12 hours for Truck processing time and 8 days for dwell time for containers (see Appendix II) along with high nautical service times (see section 1.2.2 in Table 5-PI ${ }_{1}{ }_{1}=0.05$-) with 24 hours of pre-berth waiting times leads to a low performance of Djibouti as a SSS port (see Appendix II).

The Port Indicators of Mombasa and Durban reach a close value in global terms $\left(\mathrm{PI}^{\mathrm{T}}{ }_{2}=0.30\right.$ and $\mathrm{PI}^{\mathrm{T}}{ }_{3}=0.31$ see Table 5); however, differences arise when the type of vessel $(\forall q \in \mathrm{Q})$ in the maritime stretch is considered (see 1.2 in Table 5). Durban not only achieves better results than Mombasa when a container vessel is used $\left(\mathrm{PI}^{\mathrm{T}}{ }_{31}=0.40\right.$ against $\left.\mathrm{PI}^{\mathrm{T}}{ }_{21}=0.39\right)$, but also its performance is the highest for these kinds of vessels in relation to the alternative vessels: Ro-Ro and Ro-Pax $\left(\mathrm{PI}_{31}^{\mathrm{T}}=0.40\right.$ against $\mathrm{PI}^{\mathrm{T}}{ }_{32}=0.39$ and $\mathrm{PI}^{\mathrm{T}}{ }_{33}=0.38$, see 1.2 in Table 5$)$. The trend goes in the opposite direction when Mombasa is analyzed in the maritime stretch per kind of vessels $\left(\mathrm{PI}_{21}^{\mathrm{T}}=0.39\right.$ against $\mathrm{PI}^{\mathrm{T}}{ }_{22}=0.43$ and $\mathrm{PI}^{\mathrm{T}}{ }_{23}=0.41$ item 1.2 of Table 5). This pattern is mainly due to the port times (see 1.2.1 in Table 5).

These slight variations in port times (see indicators for item 1.2.1 of Table 5) for different types of vessels operating from the same port indicate that cargo handling berth productivity was not so relevant as expected in port times. This is due to the high transit and queue times found for the cargo in the ports. These have had higher weighting value in the port times than the loading times: Mainly, the One Stop Centre Clearance Time (for example, $48 \mathrm{~h}$ in Mombasa, see Appendix IIII) and Truck processing (up to $12 \mathrm{~h}$ in Djibouti, see Appendix II).

It is notable that the highest deviations from the European standards were found for time invested in the nautical services (see 1.2.2 in Table 5: $\mathrm{PI}^{\mathrm{T}}{ }_{1}=0.05, \mathrm{PI}^{\mathrm{T}}{ }_{2}=0.08$ and $\mathrm{PI}^{\mathrm{T}}{ }_{3}=0.03$ ). This is due to the fact that this item includes actual ship waiting time with high values for all Eastern African ports; this is especially high for Durban with 41 hours (see Appendix IV) that reaches the highest deviation $\left(\mathrm{PI}^{\mathrm{T}}{ }_{3}=0.03\right.$ see Table 5$)$.

Table 6 shows the Port Indicator in terms of cost; however, this table does not show results for tug services and for loading services when Ro-Pax is used. This is so because the European standard is exempt from using a towing service for SSS transport when the vessels have the technical features assumed in this study. In addition, this analysis also assumes that the Ro-Pax uses its own drivers in loading operations. 
As can be seen in Table 6, contrary to the indicators obtained in terms of time (see Table 5), Djibouti and Mombasa offers Port Indicators over $0.5\left(\mathrm{PI}_{1}^{\mathrm{C}}=0.53\right.$ and $\mathrm{PI}_{2}{ }_{2}=0.52$ ). This represents a higher performance of these ports in terms of costs in relation to European standards. The value of this indicator $\left(\mathrm{PI}_{\mathrm{m}}^{\mathrm{C}}\right)$ is strongly influenced by the costs of the road haulages $\left(\mathrm{PI}^{\mathrm{C}}{ }_{1}=\mathrm{PI}_{2}{ }_{2}=0.54\right.$ and $\mathrm{PI}_{3}^{\mathrm{C}}=0.47$; see section 1.1 of Table 6).

The main reason for these favourable results for Djibouti and Mombasa ports is the lower unitary cost for road transport in relation to the European standards in the East Africa corridor $(1.206 \$ / \mathrm{kM}$ against $1.441 \$ / \mathrm{kM}$, see section 3.1.3). The same variable determines the lower competitiveness of Durban (1.629\$/kM against $1.441 \$ / \mathrm{kM}$, see section 3.1.3). On the other hand, considering the performance of the maritime stretch, Djibouti provides the lowest deviation regarding the European standards $\left(\mathrm{PI}_{\mathrm{m}}^{\mathrm{C}}=0.45\right.$ see section 1.2 of Table 6$)$. This is due to the fact that its tariff structure (step rates in function of vessels' gross tonnage and the port stay times) is the most suitable to the technical and operative features of the SSS vessels among the analyzed ports.

Despite this, an increasing deviation regarding the standard can be seen when the cargo units/ gross tonnage rate of the vessel is considered (from the container vessel to the Ro-Pax: $\mathrm{PI}_{11}^{\mathrm{C}}=0.50$, $\mathrm{PI}^{\mathrm{C}}{ }_{12}=0.45$ and $\mathrm{PI}^{\mathrm{C}}{ }_{13}=0.39$, see 1.2 of Table 6). This deviation in Ro-Ro and Ro-Pax vessels is even more significant for the ship duties in Mombasa $\left(\mathrm{PI}_{22}^{\mathrm{C}}=0.20\right.$ and $\mathrm{PI}_{23}=0.20$, see 1.2 .1 of Table 6) and Durban $\left(\mathrm{PI}_{32}^{\mathrm{C}}=0.25\right.$ and $\mathrm{PI}_{33}^{\mathrm{C}}=0.25$, see 1.2.1 of Table 6) due to the lack of tariff structure that adjusts to these vessels' operation under SSS conditions.

Finally, even though the loading services (stevedoring and cargo handling services) introduce closer rates to those assumed as standard for a European port leading to port indicators close to 0.5 (see 1.2.6 of Table 6: $\mathrm{PI}_{1}^{\mathrm{C}}=0.50, \mathrm{PI}_{2}{ }_{2}=0.51$ and $\mathrm{PI}_{3}^{\mathrm{C}}=0.45$ ), the load dues have proved to be very high in comparison to the European standards, with Mombasa being the port with the highest values (see 1.2.2 of Table 6: $\mathrm{PI}_{1}^{\mathrm{C}}=0.43, \mathrm{PI}_{2}^{\mathrm{C}}=0.29$ and $\mathrm{PI}_{3}^{\mathrm{C}}=0.32$ ).

\section{Conclusions}

Evaluation of the intermodal capacities of ports is usually constrained to several PPIs, especially lead-time indicators, which are independently analyzed. This evaluation involves partial approaches to port complexity, which offers incomplete diagnostics about the port performance related to SSS activity. This paper seeks to address this knowledge gap by introducing a new assessment method of the port as a load consolidation centre in intermodal chains, articulated through SSS. This method evaluates the competitiveness of the intermodal chains in terms of time and costs, by integrating the performance of the capillary hauls of the hinterland along with port operations in aggregated Port Indicators $\left(\mathrm{PI}_{\mathrm{m}} ; \forall m \in \mathrm{M}\right)$. In such a way, the interdependencies between port and hinterland features are considered. Additionally, the method shows relative evaluations to a standard previously defined by the evaluator, which permits not only benchmarking but also deviation analysis by stakeholders.

The method introduced in this paper was applied to the East African region, assuming three extreme-nodes per port, to articulate the possible capillary hauls of the ports (the 'one-to-many' model). This involved the adaptation to the Eastern African region of cost and time models for the intermodality through SSS (previously published by Martínez-López, Kronbak, and Jiang 2015a). Additionally, due to the availability of the accurate information about SSS operations, data from medium-size European SSS port were taken as standard values for the evaluation.

A number of findings can be highlighted from the application case. Specifically, there are four ports that present a good opportunity for SSS regardless of their connectivity to road or train: Djibouti, Mombasa, Beira and Durban. In fact, Mombasa and Beira's prime locations have been especially noted in relation to landlocked countries (South Sudan, Uganda, Zambia, Zimbabwe and Malawi). Specific simulations with Djibouti, Mombasa and Durban show that, despite the fact that no port reaches the European standard of an effective SSS service, Mombasa offers the best performance, followed by Durban and Djibouti. The simulations confirmed the significant 
influence of road performance on the competitiveness of intermodal chains (as previous publications have done). Whereas Port Indicators, in terms of costs, suggest that East African ports have good performance, their results in terms of time show significant port inefficiencies. Cargo handling productivity was not as significant in the overall results as expected, mainly due to its reduced influence in the calculation of port times versus the high transit and queue times found for cargo in ports. In particular, 'One Stop Centre Clearance Time' and time in truck processing had the highest impact on 'global cargo dwell time'. Moreover, times invested in nautical operations have proved to be key in time deviation in comparison with the standard European port. Its significance can be found in the long waiting time of pre-berthing vessels. Among other measures, the European ports enable the reduction of these times by exempting towing services (and sometimes the pilot service) for SSS vessels under certain technical conditions.

The cost deviation found for all ports in the maritime stretch is highly dependent on the kind of vessel involved, due to port tariff structures, which directly relate the gross tonnage (or the volume) of the vessels with fees. This involves a significant disadvantage for rolled cargo vessels' ship duties, as these vessels have high gross tonnage but fewer cargo units (i.e. low utilization rate of cargo space). This issue is partially resolved in the European standard port by means of adding this charge to vessel's port time (which is highly influenced by the loading time).

In light of the above, to improve intermodality's rate of success through SSS in East African ports, policy makers and port authorities should focus their efforts on linking the tariff structure in ports to the real operation of SSS and to the technical features of vessels (i.e. the low utilization ratio for cargo volume). Moreover, the pre-berthing waiting time should be minimized with a 'preference pass' for SSS vessels along with an exemption for towing and pilot services, wherever possible. Aside from improving the port times for the load (One Stop Centre Clearance Time and time in truck processing), given that capillary haul competitiveness (especially time invested in crossing borders) proved to be a key factor, efforts should focus on reviewing the implications of the free trade agreements (East African Community, Southern African Development Community, etc.) on road transport performance for loads.

Even though the previous findings are significant and, as expected, port benchmarking remains the same (regardless of the standard values assumed), in further analysis the number of extreme nodes per port should be enlarged over the assumed ones in this paper (only three per port). This is suggested not only to obtain more accurate and robust results but also to identify the most influential corridors on Port Indicators $\left(\mathrm{PI}_{\mathrm{m}} ; \forall m \in \mathrm{M}\right.$ ). This information would be very useful for stakeholders in their port strategy, and for policy makers to strengthen relationships with key countries.

\section{Notes}

1. Copper will be considered a container good in this analysis.

2. http://top.ttcanc.org/download_doc.php?docid $=150,330,853,986,769,237$

3. https://ec.europa.eu/inea/en/news-events/newsroom/eu-support-better-sea-transport-link-between-nantes-st -nazaire-and-vigo

4. https://www.apvigo.es/es/paginas/uso_de_instaciones_y_servicios

5. https://www.apvigo.es/es/descargas/descargar/4019/4226.memoria.2016.completa.pdf

6. http://www.findaport.com/port_preview/622

7. http://www.practicosdepuerto.es/webfm_send/18

8. https://www.ssatp.org/sites/ssatp/files/annual_meetings/2017/Presentations/PillarA/Port\%20Performance\% 20Indicators\%20-\%20EN.pdf

9. https://knoema.com/PRTDT2016/port-database-2014? country =1,000,300-djibouti

10. http://www.findaport.com/port_preview/622

11. https://www.kpa.co.ke/InforCenter/Documents/Tariff\%202012\%20Book\%20for\%20Website.pdf

12. https://knoema.es/PRTDT2016/port-database-2014? country $=1,000,300$-mombasa

13. https://www.ttcanc.org/dl.php?docid=51

14. http://www.findaport.com/port_preview/622 
15. https://www.transnetnationalportsauthority.net

16. https://www.portsregulator.org/images/documents/SA-port-benchmarking-report-2015-16.pdf

17. https://knoema.es/PRTDT2016/port-database-2014? country =1,000,300-mombasa

18. https://www.transnet.net/InvestorRelations/AR2017/OD\%20Reports/8335_Transnet\%202017_Port\%20term inals\%20HR.pdf

19. https://www.portsregulator.org/images/documents/Port-Capacity-and-Utilisation-Report-2015-16.pdf

20. https://www.saoga.org.za/information-hub/port-handbook/ports/durban/entering-port

\section{Acknowledgments}

Special thanks to the Editor and the reviewers for spending their time reviewing our work. Their comments have been essential to improve the manuscript. Also, we would like to thank the World Bank Group for partially funding the work collected in this publication.

\section{ORCID}

Alba Martínez-López (iD) http://orcid.org/0000-0003-4464-0600

Manuel Chica González (D) http://orcid.org/0000-0002-3580-0935

\section{Glossary}

Subscripts:

$\mathrm{A}=\{1, ., a\}$ Different stretches that integrate the intermodal chains: land and sea leg.

$\mathrm{C}=\{1, ., c\}$ Set of cost items considered to reach the minimum-required freight in maritime transport: amortization costs, financing costs, insurance costs, maintenance costs, crew costs, fuel costs, ship duties in port, load duties in port, pilot duties, towing duties, mooring duties, and loading costs.

$\mathrm{D}=\{1, ., d\}$ The land destinations (nodes) for the transport network

$\mathrm{K}=\{1, ., k\}$ The unloading ports (hubs)

$\mathrm{M}=\{1, ., m\}$ The loading ports (hubs)

$\mathrm{PP}=\{1, ., p\}$ Kinds of cargo capacity: TEUs, trucks.

$\mathrm{Q}=\{1, ., q\}$ Type of vessel (Feeder, Ro-Ro and Ro-Pax vessel)

$\mathrm{SS}=\{1, ., s\}$ Different stretches that integrate shipping time in the intermodal chains: sailing time, port pilot time and tug service time

$\mathrm{Z}=\{1, . ., z\}$ The land origins (nodes) for the transport network

Variables:

BorderTime invested in crossing the border

CKUnitary cost per kilometer $(€ / \mathrm{kM})$

$\mathrm{CMU}_{\mathrm{mq}}$ Cost of intermodal chain $(€ /(\mathrm{t} \times$ trip $)) \forall \mathrm{m} \in \mathrm{M} \wedge \forall \mathrm{q} \in \mathrm{Q}$

$\mathrm{CMU}_{\mathrm{q}}^{\mathrm{S}}$ Cost of intermodal chain for standard values $(€ /(\mathrm{t} \times$ trip) $) \forall \mathrm{m} \in \mathrm{M} \wedge \forall \mathrm{q} \in \mathrm{Q}$

$\mathrm{CMU}_{\mathrm{a}}$ Cost of one transport mode integrated in an intermodal chain $(€ /(\mathrm{t} \times \operatorname{trip})) ; \forall \mathrm{a} \in \mathrm{A}$

$\mathrm{CT}_{\mathrm{c}}$ Cost of the items that comprise the minimum required freight for maritime transport $(€) ; \forall \mathrm{c} \in \mathrm{C}$

DMThe maritime distance of the route $(\mathrm{kM})$

$\mathrm{DR}_{\mathrm{zm}}$ The capillary haul distance for intermodal chains (kM); $\forall \mathrm{z} \in \mathrm{Z} \wedge \forall \mathrm{m} \in \mathrm{M}$

$\mathrm{DR}_{\mathrm{kd}}$ The capillary haul distance for intermodal chains (kM); $\forall \mathrm{k} \in \mathrm{K} \wedge \forall \mathrm{d} \in \mathrm{D}$

GTGross Tonnage of vessels ( $\mathrm{t}$ )

MaxMaximum daily driving time (h)

PpWeight of cargo units (t); $\forall \mathrm{p} \in \mathrm{PP}$

RestMinimum driving rest $(\mathrm{h})$

TTime invested in capillary hauls at land for intermodal chains (h);

$\mathrm{TB}_{\mathrm{q}}$ Kinds of fleets; $\forall \mathrm{q} \in \mathrm{Q}$

TLLoading time in port $(\mathrm{h})$

TMTime invested in the maritime stretch of an intermodal chain (h)

$\mathrm{TMT}_{\mathrm{mq}}$ Time invested in intermodal transport (h) $\forall \mathrm{m} \in \mathrm{M} \wedge \forall \mathrm{q} \in \mathrm{Q}$

$\mathrm{TMT}_{\mathrm{q}}^{\mathrm{S}}$ Time invested in intermodal transport (h) $\forall \mathrm{q} \in \mathrm{Q}$

TPTime invested in port operations (h)

TSThe shipping time $(\mathrm{h})$

TSsThe time invested in the stretches that comprise the shipping time (h); $\forall \mathrm{s} \in \mathrm{SS}$

TWThe waiting time in port (h)

$\mathrm{X}_{\mathrm{z}}$ The relative probability of delivering a cargo unit (\%); $\forall \mathrm{z} \in \mathrm{Z}$ 
$\mathrm{X}_{\mathrm{d}}$ The relative probability of receiving a cargo unit (\%); $\forall \mathrm{d} \in \mathrm{D}$

VTMaximum permitted speed for the truck $(\mathrm{kM} / \mathrm{h})$

\section{References}

Daganzo, C. 2005. Logistic Systems Analysis. Berlin: Springer.

De Langen, P., and K. Sharypova. 2013. "Intermodal Connectivity as a Port Performance Indicator." Research in Transportation Business \& Management 8 (2013): 97-102. doi:10.1016/j.rtbm.2013.06.003.

Di Vaio, A., L. Varriale, and F. Alvinoa. 2018. "Key Performance Indicators for Developing Environmentally Sustainable and Energy Efficient Ports: Evidence from Italy.” Energy Policy 122 (2018): 229-240. doi:10.1016/j. enpol.2018.07.046.

Ha, M., Z. Yang, and Y. Seo. 2021. "Port Performance Measurement from a Multi-stakeholder Perspective." In International Encyclopedia of Transportation, edited by R. Vickerman, 396-406. Vol. 4. UK: Elsevier . doi:10.1016/ B978-0-08-102671-7.10506-8.

Ha, M., and Z. Yang. 2017. "Comparative Analysis of Port Performance Indicators: Independency and Interdependency.” Transportation Research Part A: Policy and Practice 103 (2017): 264-278. doi:10.1016/j. tra.2017.06.013.

Ha, M., Z. Yang, T. Notteboom, A. Ng, and M. Heo. 2017. "Revisiting Port Performance Measurement: A Hybrid Multi-stakeholder Framework for the Modelling of Port Performance Indicators.” Transportation Research Part E: Logistics and Transportation Review 103 (2017): 1-16. doi:10.1016/j.tre.2017.04.008.

Haralambides, H., S. Veldman, K. Van Drunen, and M. Liu. 2011. "Determinants of a Regional Port-centric Logistics Hub: The Case of East Africa." Maritime Economics and Logistics 13 (1): 78-97. doi:10.1057/mel.2010.17.

Johnson, H., and L. Styhre. 2015. "Increased Energy Efficiency in Short Sea Shipping through Decreased Time in Port." Transportation Research Part A: Policy and Practice 71 (2015): 167-178. doi:10.1016/j.tra.2014.11.008.

Marlow, P. B., and A. C. Paixao Casaca. 2004. "Short Sea Shipping and Its Role in Logistics Supply Chains: A European Perspective.” Journal of International Logistics and Trade 2 (1): 57-68. doi:10.24006/jilt.2004.2.1.57.

Martínez-López, A., J. Kronbak, and L. Jiang. 2015a. "Cost and Time Models for the Evaluation of Intermodal Chains by Using Short Sea Shipping in the North Sea Region: The Rosyth-Zeebrugge Route.” International Journal of Shipping and Transport Logistics 7 (4): 494-520. doi:10.1504/IJSTL.2015.069692.

Martínez-López, A., L. Alonso, and A. Munín. 2015b. “A Multi-criteria Decision Method for the Analysis of the Motorways of the Sea: The Application to the Case of France and Spain on the Atlantic Coast." Maritime Policy \& Management 37 (2): 285-303. doi:10.1080/03088839.2015.1039091.

Morales-Fusco, P., S. Sauri, and A. Lago. 2012. "Potential Freight Distribution Improvements Using Motorways of the Sea." Journal of Transport Geography 24 (2012): 1-11. doi:10.1016/j.jtrangeo.2012.05.007.

Ng, A. 2009. "Competitiveness of Short Sea Shipping and the Role of Port: The Case of North Europe." Maritime Policy \& Management 36 (4): 337-352. doi:10.1080/03088830903056983.

Paixao, A., and P. Marlow. 2002. "Strengths and Weaknesses of Short Sea Shipping." Marine Policy 26 (2002): 167-178. doi:10.1016/S0308-597X(01)00047-1.

Paixao Casaca, A. C. 2008. "Motorway of the Sea Port Requirements: The Viewpoint of Port Authorities." International Journal of Logistics Research and Applications 11 (4): 279-294. doi:10.1080/13675560801912254.

Sambracos, E., and M. Maniati. 2012. "Competitiveness between Short Sea Shipping and Road Freight Transport in Mainland Port Connections; the Case of Two Greek Ports.” Maritime Policy \& Management 39 (3): $321-337$. doi:10.1080/03088839.2012.671545.

Sandberg-Hanssen, T., T. A. Mathisen, and F. Jorgensen. 2012. "Generalized Transport Costs in Intermodal Freight Transport." Procedia - Social and Behavioral Sciences 54 (2012): 189-200. doi:10.1016/j.sbspro.2012.09.738.

Shiau, T. A., and C. C. Chuang. 2015. "Social Construction of Port Sustainability Indicators: A Case Study of Keelung Port." Maritime Policy \& Management 42 (1): 26-42. doi:10.1080/03088839.2013.863436.

Suárez-Alemán, A., L. Trujillo, and K. Culliane. 2014. "Time at Ports in Short Sea Shipping: When Timing Is Crucial.” Maritime Economics \& Logistics 16 (2014): 399-417. doi:10.1057/mel.2014.5.

Suárez-Alemán, T. L., F. Medda, and F. Medda. 2015. "Short Sea Shipping as Intermodal Competitor: A Theoretical Analysis of European Transport Policies.” Maritime Policy \& Management 42 (4): 317-334. doi:10.1080/ 03088839.2014.904947.

Taleb-Ibrahimi, M. 1989. "Modelling and Analysis of Container Storage in Ports.” Ph.D. Thesis. University of California. Berkeley

Teravaninthorn, S., and G. Raballand. 2009. Transport Prices and Costs in Africa. A Review of the International Corridors. Washington, DC: World Bank.

Trujillo, L., and A. Martínez-López. 2021. "Ferries and Short-sea Shipping." In International Encyclopedia of Transportation, edited by R. Vickerman, 280-285. Vol. 3. UK: Elsevier . doi:10.1016/B978-0-08-1026717.10256-8. 
Vermeiren, T., and C. Macharis. 2016. "Intermodal Land Transportation Systems and Port Choice, an Analysis of Stated Choices among Shippers in the Rhine-Scheldt Delta." Maritime Policy \& Management 43 (8): $992-1004$. doi:10.1080/03088839.2016.1172277.

\section{Appendix I. Data for the European standard port}

- Tariff Book for Vigo Port. ${ }^{4}$

- Port facilities: 5 STS cranes (Annual Report 2017, Port of Vigo) ${ }^{5}$

- 6 fixed ramps for Ro-Ro traffic and one mobile ramp.

- Technical characteristics for standard vessels are assumed from Table 1

- Port Performance Indicators (Annual Report 2017, Port of Vigo):

- Berth Productivity for container terminal: 60 movements/h and ship

- Port Performance Indicators:

- Dwell Time for containers: 3 days for cargo (not from/to the EU)

- Waiting time before berth for container vessels (from the time the vessel arrives at the fairway buoy to the time at its first berth, this involves pilot, towing and actual ship waiting time): $0.75 \mathrm{~h}$

○ Truck processing time for receipt and delivery of cargo (turnaround time) - average (hours):0.5 hour

- The actual ship waiting time: 0.75 hours

Time Taken at the Document Processing Centre (DPC): 0.5 hours

- One Stop Centre Clearance Time: less than 8 hours (import/export; non EU cargo)

- Loading/unloading Ro-Ro rate: 40 units/hour per ship

- Master Harbour Office ${ }^{6}$ :

- Tugboat utilization for entrance and departure is not necessary.

- General Regulation about pilotage in Spain (RD 393/1996, first March, article 8) ${ }^{7}$ :

- Pilotage service is compulsory for vessels over 500 GT for entry and exit of port.

\section{Appendix II. Data for Djibouti port}

- The land nodes (see Table 1): Djibouti, Addis Ababa (Ethiopia) and Dire Dawa (Ethiopia).

- Tariff Book for Djibouti Ports 1 January 2018

- Technical characteristics for standard container vessel assumed (see Table 1)

- Port Performance Indicators: Data availability and data collection methods in 10 African Pilot ports (De Langen and Sharypova, 2013) ${ }^{8}$ :

○ Berth Productivity for container terminal: 35.3 movements/h and ship (2015)

- African Development Bank Group ${ }^{9}$ (2008):

○ Dwell Time for containers: eight days

- Waiting time before berth for container vessels (from the time the vessel arrives at the fairway buoy to the time at its first berth, this involves pilot, towing and ship actual waiting time): 1 day.

○ Truck processing time for receipt and delivery of cargo (turnaround time) -average (hours): 12 hours

- Master Harbour Office ${ }^{10}$ :

- Compulsory pilotage for all vessels with a net tonnage over 300 tones. The service must be requested 1.5 hours before it is needed.

○ Two tugs are required when manoeuvering within the port.

\section{Appendix III. Data for Mombasa port}

- The land nodes (see Table 1): Nairobi (Kenya), Yuba (South Sudan) and Kampala (Uganda).

- Tariff Book (Kenya Port Authorities, 2012) ${ }^{11}$ updated to 2017 values through CPI.

- Technical characteristics for standard container vessel assumed (see Table 1)

- Port Performance Indicators: Data availability and data collection methods in 10 African Pilot ports (De Langen and Sharypova, 2013) ${ }^{8}$ :

- Berth Productivity for container terminal: 24.3 movements/h and ship (2015)

- African Development Bank Group ${ }^{12}$ (2006):

- Truck processing time for receipt and delivery of cargo (turnaround time)-average (hours): 4.5 hours

- The Northern Corridor Transit and Transport Coordination Authority (NCTTCA) ${ }^{13}$ (Monthly Port Community Charter Report for July 2017):

○ Dwell Time for containers: $90 \mathrm{~h}$ (3.75 days) 


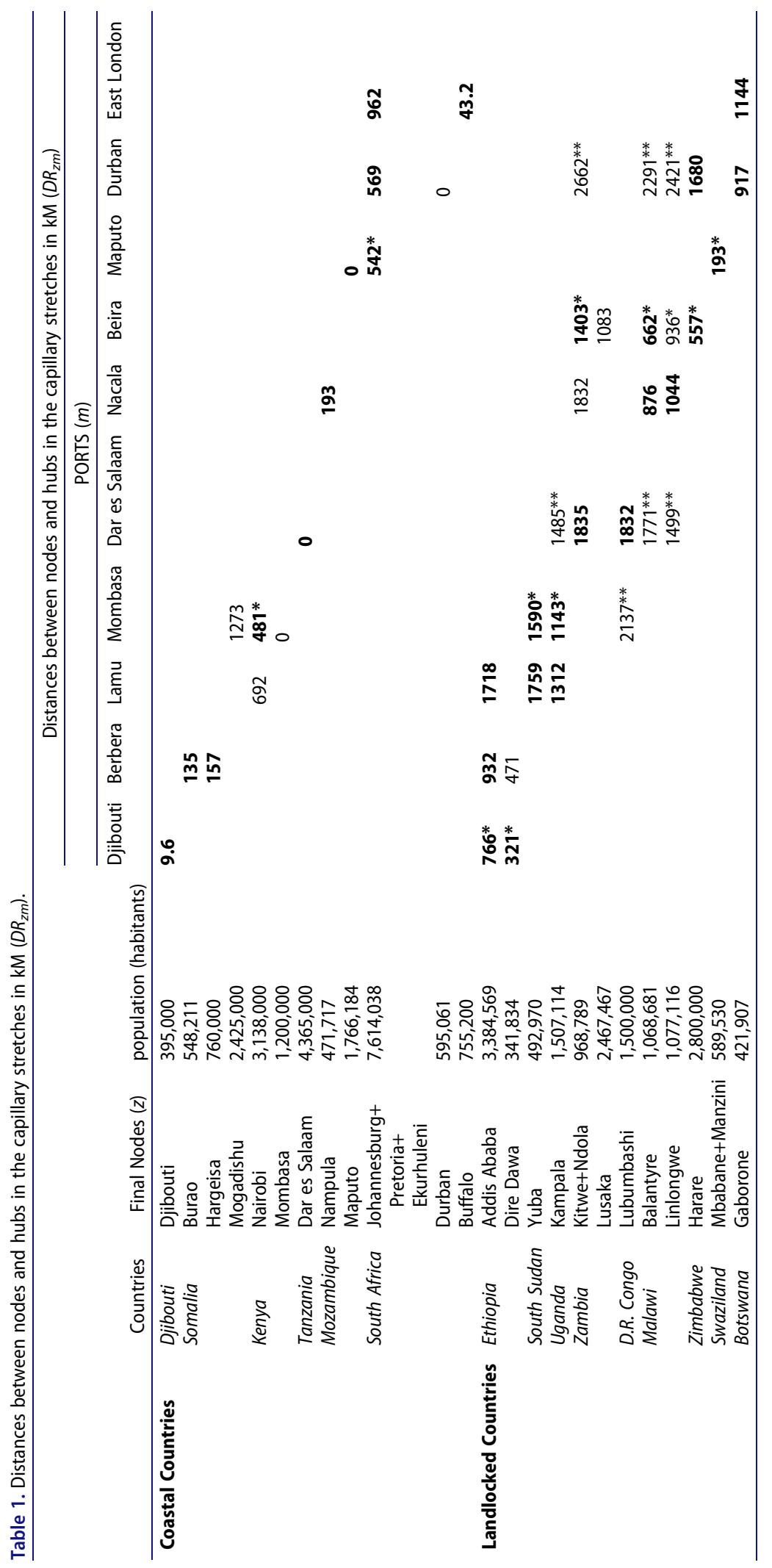


Table 2. Technical features for standard vessels operating under SSS conditions.

\begin{tabular}{llll}
\hline Features & \multicolumn{1}{c}{ Feeder } & Ro-Ro & Ro-Pax \\
\hline Gross tonnage (GT) & 10,585 & 15,224 & 41,700 \\
Volume (m3) & 35,000 & 51,730 & 137,728 \\
Cargo units & 1036 TEUs & 105 trucks & 173 trucks \\
Vessel speed VB (Kn) & 19.3 & 19.5 & 21 \\
Current Maritime distance DM (n.m) & 393 & 494 & 532 \\
Reference Vessel & Conmar Bay & La Surprise & MV Pont-Aven \\
& (IMO: 9,458,975) & $($ IMO: 9,198,719) & (IMO: 9,268,708) \\
Shipping Company & Unifeeder Shipping Company & Suardiaz & Britany Ferry \\
\hline
\end{tabular}

Table 3. Variables assumed to calculate the time invested in capillary hauls.

\begin{tabular}{lccc}
\hline Corridor & $\operatorname{Max}(\mathrm{h})$ & Rest $(\mathrm{h})$ & Border $(\mathrm{h})$ \\
\hline Eastern Africa & 6 & 2 & 24 \\
Southern Africa & 8 & 1.5 & 24 \\
European Union & 9 & 0.75 & 0 \\
\hline
\end{tabular}

Table 4. Overall port indicators to articulate intermodal chains through SSS.

\begin{tabular}{lll}
\hline Djibouti & $\mathrm{Pl}_{1}$ & 0.37 \\
\hline Mombasa & $\mathrm{PI}_{2}$ & $\mathbf{0 . 4 1}$ \\
Durban & $\mathrm{PI}_{3}$ & $\mathbf{0 . 3 8}$ \\
\hline
\end{tabular}

Table 5. Port indicators in terms of time for the Eastern African ports operating as consolidation centres of cargo for intermodal chains.

\begin{tabular}{|c|c|c|c|c|c|}
\hline & & Container $\left(\mathrm{PI}_{\mathrm{m} 1}^{\top}\right)$ & $\begin{array}{l}\text { Ro-Ro } \\
\left(\mathrm{PI}_{\mathrm{m} 2}^{\top}\right)\end{array}$ & $\begin{array}{l}\text { Ro-Pax } \\
\left(\mathrm{PI}_{\mathrm{m} 3}^{\top}\right)\end{array}$ & $\mathrm{PI}_{\mathrm{m}}^{\top}$ \\
\hline \multirow[t]{3}{*}{ 1.-Intermodal transport } & Djibouti $(m=1)$ & 0.22 & 0.21 & 0.21 & 0.21 \\
\hline & Mombasa $(m=2)$ & 0.30 & 0.30 & 0.30 & 0.30 \\
\hline & Durban $(m=3)$ & 0.32 & 0.30 & 0.30 & 0.31 \\
\hline \multirow[t]{3}{*}{ 1.1-Time invested in the land stretches } & Djibouti $(m=1)$ & 0.06 & 0.06 & 0.06 & 0.06 \\
\hline & Mombasa $(m=2)$ & 0.13 & 0.13 & 0.13 & 0.13 \\
\hline & Durban $(m=3)$ & 0.16 & 0.16 & 0.16 & 0.16 \\
\hline \multirow[t]{3}{*}{ 1.2-Time invested in maritime stretch } & Djibouti $(m=1)$ & 0.28 & 0.27 & 0.27 & 0.27 \\
\hline & Mombasa $(m=2)$ & 0.39 & 0.43 & 0.41 & 0.41 \\
\hline & Durban $(m=3)$ & 0.40 & 0.39 & 0.38 & 0.39 \\
\hline \multirow[t]{3}{*}{ 1.2.1.Port Times } & Djibouti $(m=1)$ & 0.29 & 0.28 & 0.28 & 0.28 \\
\hline & Mombasa $(m=2)$ & 0.40 & 0.45 & 0.43 & 0.43 \\
\hline & Durban $(m=3)$ & 0.44 & 0.43 & 0.43 & 0.43 \\
\hline \multirow[t]{3}{*}{ 1.2.2. $T S_{2}+T S_{3}$} & Djibouti $(m=1)$ & 0.05 & 0.05 & 0.05 & 0.05 \\
\hline & Mombasa $(m=2)$ & 0.08 & 0.08 & 0.08 & 0.08 \\
\hline & Durban $(m=3)$ & 0.03 & 0.03 & 0.03 & 0.03 \\
\hline
\end{tabular}

- Waiting time before berth for container vessels (from the time the vessel arrives at the fairway buoy to the time at its first berth, this involves pilot, towing and actual ship waiting time): 17 hours.

○ The actual ship waiting time: 16.15 hours

○ Time Taken at the Document Processing Centre (DPC): 1.87 hours

- One Stop Centre Clearance Time: 48 hours

- Delay after customs release: 41 hours

- Master Harbour Office ${ }^{14}$ :

- Compulsory for all vessels unless exempted by the Port Authority (less than 500 GT according to the exceptions collected in the Tariff book)

○ Tugs are compulsory when ordered by pilots. 
Table 6. Port indicators in terms of cost for the Eastern African ports operating as consolidation centres of cargo for intermodal chains.

\begin{tabular}{|c|c|c|c|c|c|}
\hline & & Container $\left(\mathrm{PI}_{\mathrm{m} 1}^{\mathrm{C}}\right)$ & $\begin{array}{l}\text { Ro-Ro } \\
\left(\mathrm{Pl}^{C}{ }_{\mathrm{m} 2}\right)\end{array}$ & $\operatorname{Ro}-\operatorname{Pax}\left(\mathrm{PI}_{\mathrm{m} 3}^{\mathrm{C}}\right)$ & $\mathrm{PI}_{\mathrm{m}}^{\mathrm{C}}$ \\
\hline \multirow[t]{3}{*}{ 1. Intermodal transport } & Djibouti $(m=1)$ & 0.54 & 0.52 & 0.53 & 0.53 \\
\hline & Mombasa $(m=2)$ & 0.53 & 0.51 & 0.51 & 0.52 \\
\hline & Durban $(m=3)$ & 0.46 & 0.45 & 0.46 & 0.46 \\
\hline \multirow[t]{3}{*}{ 1.1 Costs of the land stretches } & Djibouti $(m=1)$ & 0.54 & 0.54 & 0.54 & 0.54 \\
\hline & Mombasa $(m=2)$ & 0.54 & 0.54 & 0.54 & 0.54 \\
\hline & Durban $(m=3)$ & 0.47 & 0.47 & 0.47 & 0.47 \\
\hline \multirow[t]{3}{*}{ 1.2 Cost of the maritime stretch } & Djibouti $(m=1)$ & 0.50 & 0.45 & 0.39 & 0.45 \\
\hline & Mombasa $(m=2)$ & 0.47 & 0.37 & 0.26 & 0.36 \\
\hline & Durban $(m=3)$ & 0.40 & 0.37 & 0.35 & 0.37 \\
\hline \multirow[t]{3}{*}{ 1.2.1 The ship duty } & Djibouti $(m=1)$ & 0.74 & 0.42 & 0.44 & 0.54 \\
\hline & Mombasa $(m=2)$ & 0.59 & 0.20 & 0.20 & 0.33 \\
\hline & Durban $(m=3)$ & 0.63 & 0.25 & 0.25 & 0.37 \\
\hline \multirow[t]{3}{*}{ 1.2.2 The load duty } & Djibouti $(m=1)$ & 0.49 & 0.40 & 0.40 & 0.43 \\
\hline & Mombasa $(m=2)$ & 0.29 & 0.27 & 0.30 & 0.29 \\
\hline & Durban $(m=3)$ & 0.23 & 0.34 & 0.40 & 0.32 \\
\hline \multirow[t]{3}{*}{ 1.2.3 The pilot duty } & Djibouti $(m=1)$ & 0.63 & 0.53 & 0.32 & 0.49 \\
\hline & Mombasa $(m=2)$ & 0.43 & 0.35 & 0.16 & 0.31 \\
\hline & Durban $(m=3)$ & 0.36 & 0.35 & 0.32 & 0.34 \\
\hline \multirow[t]{3}{*}{ 1.2.4 The tug services } & Djibouti $(m=1)$ & - & - & - & - \\
\hline & Mombasa $(m=2)$ & - & - & - & - \\
\hline & Durban $(m=3)$ & - & - & - & - \\
\hline \multirow[t]{3}{*}{ 1.2.5 The mooring services } & Djibouti $(m=1)$ & 0.57 & 0.57 & 0.44 & 0.49 \\
\hline & Mombasa $(m=2)$ & 0.44 & 0.38 & 0.32 & 0.38 \\
\hline & Durban $(m=3)$ & 0.81 & 0.77 & 0.72 & 0.76 \\
\hline \multirow[t]{3}{*}{ 1.2.6 The loading services } & Djibouti $(m=1)$ & 0.50 & 0.50 & - & 0.50 \\
\hline & Mombasa $(m=2)$ & 0.55 & 0.47 & - & 0.51 \\
\hline & Durban $(m=3)$ & 0.49 & 0.41 & - & 0.45 \\
\hline
\end{tabular}

\section{Appendix IV. Data for Durban port}

- The land nodes (see Table 1): Johannesburg-Pretoria-Ekurhuleni (South Africa), Harare (Zimbabwe) and Gaborone (Botswana).

- Tariff Book 2016-2017 (Transnet, 2016). ${ }^{15}$

- CMA CGM Shipping Agencies South Africa 2017 Tariff Guide

- Technical characteristics for standard container vessel assumed (see Table 1)

- Ports Regulator of South Africa (Port Benchmarking report: SA Terminals 2015/16 ${ }^{16}$ )

- Berth Productivity for container terminal: 58 movements/h and ship (DCT Pier 2)

- Cargo Dwell Time for South African ports: 3.93 days

- Waiting time before berth for container vessels (from the time the vessel arrives at the fairway buoy to the time at its first berth, this involves pilot, towing and ship actual waiting time): $41 \mathrm{~h}(3.4 \mathrm{~h}$ spent in the per pilot service)

- African Development Bank Group ${ }^{17}$ :

- Dwell Time for containers: 4 days (2006)

- TRANSNET Port Terminals $2017^{18}$

- Truck processing time for receipt and delivery of cargo (turnaround time) - average (hours): 79 minutes

- Port Regulators of South Africa (South African Port Capacity and Utilization Report 2015/16 ${ }^{19}$ )

- Loading/unloading Ro-Ro rate: 44 units/hour per ship

- Saoga (South African Oil and Gas Alliance) ${ }^{20}$ :

- Pilotage: Compulsory for all vessels

- Tug attendance is compulsory. 